\title{
Digital Learning Across Boundaries (DLAB): Immersive technologies supporting changemaking in an international context
}

Aprendizaje digital a través de las fronteras: tecnologías inmersivas que apoyan la creación de cambios en un contexto internacional

Aprenentatge digital a través de les fronteres: tecnologies immersives que donen suport a la creació de canvis en un context internacional

\author{
Emma Whewell ${ }^{1, * \odot}$, Helen Caldwell ${ }^{\circledR \odot}$, Beth Garrett ${ }^{3 \odot}$, Grant Malloch ${ }^{3 \odot}$ \\ 1 | Faculty of Arts, Science and Technology, University of Northampton, Waterside Campus, Northampton, \\ United Kingdom \\ 2 | Faculty of Health, Education and Society, University of Northampton, Waterside Campus, Northampton, \\ United Kingdom \\ 3 | University of Northampton, Northampton, United Kingdom \\ ${ }^{*}$ Corresponding author: emma.whewell@northampton.ac.uk (Emma Whewell)
}

Received: 07/27/2020 | Accepted: 04/13/2021 | Published: 07/19/2021

Citation: Whewell, E., Caldwell, H., Garrett, B. \& Malloch, G. (2021). Digital Learning Across Boundaries (DLAB): Immersive technologies supporting changemaking in an international context. Research in Education and Learning Innovation Archives, 27,19-32. 10.7203/realia.27.18019

Copyright: The Authors. Open Access: This article is distributed under the terms of the Creative Commons Attribution-NoDerivatives 4.0 International licence (CC BY-ND 4.0)

Funding: None informed
ABSTRACT: The Digital Learning Across Boundaries: Developing Changemakers (DLAB) project uses immersive technologies in education to explore three challenges across three years: physical, personal and environmental. This paper focuses on the first of these, bringing together the themes of digital making and changemaking to cross physical boundaries by raising awareness about physical inactivity in 11 and 12 year old school pupils. Immersive technologies such as augmented and virtual reality enabled the development of empathy and intercultural understanding among participants, fostered an understanding of changemaking, and created environments for sharing prototype exergames. Research data is analysed to seek evidence of the development of changemaker attributes and impact within a sample group of 60 English school pupils.

KEYWORDS: Digital literacy; Changing society; Social dynamics; Social progress; Educational technology

RESUMEN: El proyecto Digital Learning Across Boundaries: Developing Changemakers (DLAB) utiliza tecnologías inmersivas en educación para explorar tres desafíos a lo largo de tres años: físico, personal y ambiental. Este documento se centra en el primero de estos, que reúne los temas de la creación digital y la creación de cambios para cruzar los límites físicos al crear conciencia sobre la inactividad física en los alumnos de 11 y 12 años de edad. Las tecnologías inmersivas, como la realidad aumentada y virtual, permitieron el desarrollo de la empatía y la comprensión intercultural entre los participantes, fomentaron la comprensión de la creación de cambios y crearon entornos para compartir prototipos de juegos de ejercicios. Los datos de la investigación se analizan para buscar evidencia del desarrollo de los atributos y el impacto de los creadores de cambios dentro de un grupo de muestra de 60 alumnos de inglés.

PALABRAS CLAVE: Alfabetización digital; Cambiando la sociedad; Dinámica social; Progreso social; Tecnologia Educacional

RESUM: El projecte digital Learning Across Boundaries: Developing Changemakers (DLAB) fa servir tecnologies immersives en educació per explorar tres reptes al llarg de tres anys: físic, personal 
i ambiental. Aquest treball se centra en el primer d'aquests, que reuneix els temes de l'elaboració digital i el canvi de dades per a traspassar les fronteres físiques mitjançant la sensibilització sobre la inactivitat física dels estudiants d'11 i 12 anys. Tecnologies immersives, com la realitat augmentada i virtual, van permetre el desenvolupament de l'empatia i la comprensió intercultural entre els participants, van fomentar la comprensió del canvi de canvis i van crear entorns per a compartir exercicis de prototips. Les dades de la investigació s'analitzen per cercar proves del desenvolupament d'atributs i canvis d'impacte en un grup d'exemple de 60 alumnes d'anglès.

PARAULES CLAU: alfabetització digital; canvi de societat; dinàmica social; progrés social; tecnologia educativa

Practitioner Notes

What is currently known about the subject?

- This paper builds on research related to AR and VR in educational fields. It explores the role of immersive technologies in social innovation education and the notion of changemaking. The current status of health and physical activity in young people is a global issue and there is much debate relating to the role of gaming and technology in contributing to sedentary behaviours. Immersive technologies are appealing to young people and there is a growing drive to incite change and be creators and innovators. This work draws on the maker movement and combines the notion of digital making with changemaking.

\section{What this paper adds?}

- This study is pioneering in its use of AR and VR technology in an educational context by demonstrating that the creative use of immersive technologies, supported by a mix of other technologies, has the potential to enable young people to recognise social dilemmas, plan collaboratively, and design and make prototype solutions. It presents an original set of data that suggests that the creative use of technologies such as AR and VR might develop changemaker attributes and an understanding of the changemaker process within an international project, providing compelling evidence that there is much potential for technology-enabled changemaking in education.

\section{Implications of this work for practice and future policy?}

- Whilst immersive technology use in schools is in its infancy, this study indicates that there is a willingness and excitement to develop it as a learning tool and as a pedagogical approach. This work identifies the potential to develop exergaming in relation to health, physical activity, sport and physical education on a wider scale. It also identifies opportunities to explore social and environmental issues through AR and VR within the context of social innovation education. The work highlights the enabling power of technologies in acting as a catalyst for transformative learning, promoting the aims of UNESCO's Sustainable Development Goal 4, Target 7 that focuses on promoting sustainable societies and global citizenship through education (UN, 2015).

\section{INTRODUCTION}

The DLAB project addresses the need to align European educational practice with ways in which digital technology is changing how and what we learn, and how this is applied in education. In pursuing these goals, DLAB is inspired by the changemaker movement which seeks to build the skills and attributes for individuals to find innovative solutions to society's challenges. Key themes of the project include the development of changemakers and social innovation education, supported by innovative digital learning environments which incorporate immersive technologies, such as augmented and virtual reality (AR and VR). These tools blend physical and digital learning environments and provide powerful opportunities for international collaboration. International, in the context of this study, refers to the five European countries involved in the DLAB project: Belgium, Denmark, England, Norway and Spain. 
The study brings together two aspects of the maker movement: digital making and changemaking through an ethnographic participatory methodology. Our participants identified the social issue of the negative association of technology with physical inactivity. They sought to explore the problem of childhood physical inactivity and the potential solution of exergaming as the context for changemaking. The term 'exergaming' has been used to refer to gaming which uses controllers that are moved with large bodily movements (Faric et al., 2019). In the context of this study the definition is broadened to include a range of technologies supporting physical activity.

The DLAB project will run for three years and involves around fifty university lecturers, student teachers and school teachers, together with ten classes of school pupils across five European countries. Participants collaborate at a distance to explore various 'learning across boundaries' challenges (physical, personal and environmental). This paper focuses on the work of one sub-group from the first year of the project, consisting of paired classes of 11 and 12 year old children in England and Denmark who undertook the challenge of crossing physical boundaries. Inspired by the Sports Innovation Campus at Howest University in Bruges, these participants collaborated to invent and share prototype exergames that reversed the negative association of technology with physical inactivity. The research strand of the project investigated how technology supported pupils' development of changemaker attributes and impact. The English team consisted of four university lecturers, six university students, two teachers and two classes of pupils. Research data includes photo elicitations, observations and focus group interviews with pupils collected before, during and after participation in the collaborative activities.

The potential for immersive technologies to support changemaking in an educational context was explored through the following research questions:

1. Can digital technologies, such as VR and AR, help school pupils to develop changemaker attributes?

2. Can digital technologies, such as VR and AR, help school pupils to develop changemaker impact?

\subsection{Review of Literature}

We review literature pertaining to the use of AR and VR technology in physical activity settings in schools, relating this to the notion of changemakers and how it supports the development of skills associated with changemaking. Changemaking can be defined as a process of designing, refining, implementing and evaluating an innovation (Thorogood, Azuma, Collins, Plyushteva, \& Marie, 2018) and might be promoted through activities that develop 'soft skills' which are not easily taught, including project management, persuasion, teamwork and leadership. At the heart of the process is "the active, engaged student who does not passively consume knowledge but who is active in creating it" (Thorogood et al., 2018, 544). Alden-Rivers, Armellini, Maxwell, Allen, and Durkin (2015) recognize the complex nature of changemaking, highlighting the ability to identify an issue and take positive action as one of an array of relevant attributes.

Links have been identified between changemaking and critical learning theory (United-Nations, 2015). The latter looks to develop attributes linked with social responsibilities, such as social conscience and empathy, allowing learners to acquire and analyse both social and self-knowledge (Mclaren \& Crawford, 2010). Additionally, critical learning theory encourages learners to develop empathy, critical thinking and civil responsibility (Scorza, Mirra, \& Morrell, 2013), attributes central to changemaking. Connections can also be made between changemaking and employability, through its emphasis on empathy, creativity and reflection (UnitedNations, 2015). Whilst changemaker skills are not necessarily new, they are 
contemporary, as there is "an expectation for young people to be the social leaders and innovators of tomorrow" (Alden-Rivers et al., 2015, 11)

Intercultural competence has been defined as "the skills needed to function effectively in interactions with people who differ from an individual linguistically or culturally" (Dziedziewicz, Gajda, and Karwowski, 214, 32). Importantly, it develops sensitivities around gender and diversity, and is concurrent with changemaking which similarly emphasises empathy, tolerance, respect and appreciation. Dziedziewicz et al. (2014) suggest that collaborating with people from different countries and cultures builds creativity and breaks down barriers, however they acknowledge that few such programmes focus on children. This study recognises both intercultural competence and intercultural awareness and adds to the debate of how to build both in children and young people by investigating the impact of international teams working together to solve social problems they have jointly identified.

The studies cited above emphasise the combination of empathy for others with the motivation to take creative action to solve problems, recognising that this ability is favoured by employers. The inclusion of digital competencies to this skill set makes it consistent with the transformative ambitions of the United Nations (UN) Sustainable Development Goal (SDG) 4.7 which promotes sustainable development and global citizenship (Mochizuki, 2019; United-Nations, 2015). A similar combination of skills is recognised by Hughes and Maas (2017), who explored the use of AR and VR with marginalised young people. They found the addition of technologies enhanced students' ability to collaborate and communicate, and helped develop 'transferable life skills' such as resilience and problem solving. They suggest that digital creativity facilitates the development of jointly-constructed understandings and shared beliefs, both of which have been identified as having a positive impact on the development of changemaker attributes (Alden-Rivers et al., 2015).

AR and VR have recently begun to appear more frequently in educational contexts (Hughes \& Maas, 2017). VR technology "completely immerses users in a synthetic world without seeing the real world" (Carmigniani et al., 2011, 342). In contrast, AR superimposes information or virtual objects into the real world, allowing a reality where virtual objects seem to coexist in the real environment (Azuma, 1997). Lin and Chang (2015) recognise that these technologies have in the past been cost prohibitive; however, recent advancements have made them more accessible and particularly well suited to use by children. Faric et al. (2019) highlight numerous studies that report increases in intensity of physical activity and higher ratings of enjoyment and interest through AR, noting that the immersive qualities are likely to distract participants from the physical exertion. Similarly, Thornton, Ernst, and Clark $(2012,18)$ observe that AR and VR by their very nature have "the potential to both engage and excite". This represents an opportunity within educational settings to embed authentic learning experiences that facilitate cognitive immersion and engagement with physical activity through AR or VR.

AR and VR technologies pose further benefits for multi-sensory and active learning. Lin and Chang (2015) conducted a small scale study within a special educational needs setting using a body motion interactive game developed in Scratch and found that the use of AR had a significant and positive effect on children's physical activity levels. They stress the ease of interaction afforded by AR and suggest that games which rely upon sensory and movement control are more successful and accessible. Hughes and Maas (2017) similarly found benefits of AR for children with special needs, including "increased content understanding of spatial structure and function, learning of language associations, long term memory retention, improved physical task performance and increased motivation and engagement". They conclude that AR and VR appeal to the sensory nature of learning by drawing upon auditory, visual and spatial skills, making it a more immersive experience. As noted by Wu, Lee, Chang, and 
Liang (2013), this style of learning contrasts conventional teacher-centred pedagogies and can promote transformational learning, which focuses on individuals' learning needs. Transformational learning allows learners to develop skills they themselves feel they need to improve. The focus is on the impact of learners' critical reflections and discussion of their experiences (Fazio-Griffith \& Ballard, 2016). Through firsthand, practical experiences and activities, transformational learning allows learners to explore and develop changemaker attributes (Alden-Rivers et al., 2015) .

This review of literature highlights the potential for AR and VR to promote active engagement with physical activity and suggest that they can improve accessibility, engagement and changemaking skills for many learners. It sets the scene for our investigation into the potential for using digital technologies to create exergames supporting the development of changemaker attributes and impact.

\section{METHODOLOGY}

This study employed an ethnographic participatory research methodology with the intention of gaining rich insights into the role of digital technology in building pupils' beliefs and behaviours related to the concept of changemaking (BMJ, 2008). Recognising that cameras and digital images are a constant presence in children's lives and are integral to their visual cultures, we drew from visual ethnography approaches such as photo elicitation to link pupil reflection with the learning contexts (Pink, 2013). This acknowledges that visual ethnography can itself be part of the learning process rather than just data collection (Pink, 2013). We sought to use images to empower participants to develop metacognition around the process of changemaking and articulate its impact on their behaviours and beliefs.

The participatory research framework in this study encouraged school pupils and university students to see themselves as co-researchers alongside the teachers and lecturers. This resonates with the work of Thorogood et al. (2018), who found that reconfiguring the relationships between research participants, so that all were equal partners, was conducive to changemaking. In our view, the approach increased participants' ownership of the project and engaged them at a deeper level, meaning they were more likely to develop the self-efficacy needed to become changemakers.

The sample for this study included two classes of English Year 7 pupils (aged 11-12 years old), supported by two class teachers, six Initial Teacher Training students and four lecturers from the University of Northampton. All participants were volunteers, project partners or, in respect to the pupils, classes selected to join in with the project activities. The research employed a convenience sampling approach as the schools involved in the project selected two homogenous classes in each country to participate (Cohen, Manion, \& Morrison, 2018). Our data analysis focuses upon reflections from the pupils in the UK, however, their responses are based upon interactions with their peers in Denmark.

Ethical approval was obtained from the university and British Educational Research Association (British-Educational-Research-Association, 2018) guidelines were followed. All participants were invited to take part in the study, anonymity was guaranteed, and they had withdrawal rights throughout. British-EducationalResearch-Association (2018) supports the notion of consent as it applies to children and young people, and ethical approval was sought from both the children involved and the Headteacher as is recognised gatekeeping practice. In line with the United Nations' Convention on the Rights of the Child (United-Nations, 1989), the best interests of the pupils were the primary consideration, and information and support were presented in an open and child appropriate manner.

Routine tracks of reflection were built into the research process to provide a regular insight into the lived experience of the collaborative days when the pairs of 
classes worked concurrently in the two countries by gathering data before, within and after action. Participants were made explicitly aware of the opportunities to contribute to this reflective cycle (Schon, 1984). The use of pupils' own photos of their activities increased their autonomy to choose what to share and helped to shift the emphasis away from the researcher-participant dynamic (Kara, 2015). Pupils were asked to take pictures using their phones at points during the collaborative days when they felt particularly motivated and these were combined in a Padlet. A week after each collaborative day, the pupils selected three photos and wrote briefly about them. These formed the basis for short, recorded interviews with students and lecturers. Throughout the collaborative days, the university students made field notes of their observations.

Data was thus gathered through several mediums: transcribed individual interviews and focus groups with pupils, analysis of images, pupil comments on images, and field notes made by students during the collaborative days. In total, six recorded focus group interviews covering approximately two hours, accompanying images with comments, and three sets of student observations were analysed. The project did not intend to make wider generalisations and the samples were taken from those groups who offered a complete set of data.

\subsection{Use of technologies}

This section demonstrates the technologies used to facilitate the creation of exergames in response to the social problem of childhood physical inactivity.

Firstly, AR and VR enabled the development of mutual understanding between pupils in England and Denmark at the beginning of the project as they used various tools to get to know each other and to understand their social and educational contexts. These social activities included:

- the exchange of seasonal greetings through the creation of AR Keynote GIFs triggered by the app EyeJack;

- swapping $360^{\circ}$ stills and videos of their classrooms and creating $360^{\circ}$ tours of each other's local environments;

- sharing virtual meals in AR and VR via CoSpaces;

- exploring landmarks in each other's countries in $360^{\circ}$ through Google Earth tours.

Figure 1 represents the sharing of favourite meals developed in Co Spaces and 360 films of their school shared between countries.

Secondly, pupils designed and exchanged digital artefacts during collaborative days, where pupils in both countries worked synchronously on their exergame projects, aided by collaborative tools such as video communication and Twitter. Their invented exergames included:

- combining the app Plankpad with balance boards and VR headsets;

- creating a soccer video sensing game using a webcam in the coding environment Scratch;

- challenging international partners to explore an environment with the Cardboard Camera app;

- playing a giant human Pac-Man game using MakeyMakeys connected with electric fence string and tin foil;

- creating basketball coaching videos in VR;

- remixing a balance board challenge using Microbits and Scratch. 


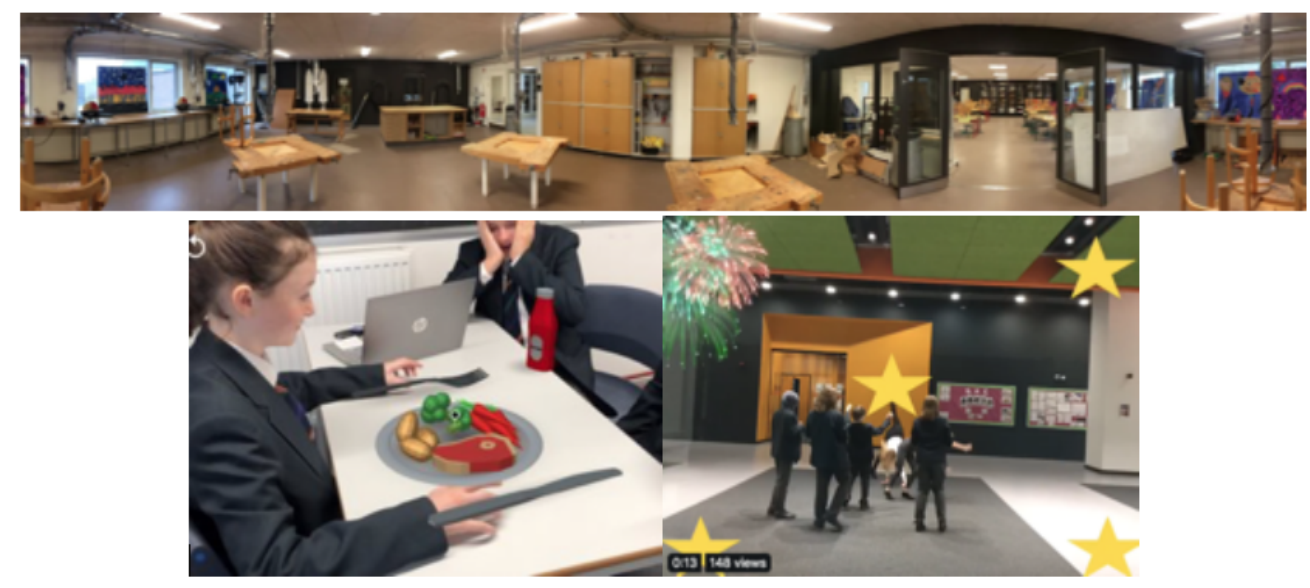

Figure 1. Use of technologies for getting to know each other

These examples illustrate some ways in which digital making and creative use of immersive technology can support changemaking. They combine to make a set of digital tools and strategies for connecting classrooms and enabling pupils to jointly create prototype artefacts and environments that represent innovative solutions to the social issue of physical inactivity.

\section{ANALYSIS AND RESULTS}

The data was examined through an iterative process of thematic coding in relation to the research questions. This process was repeated and modified by team members to ensure consistency and shared understanding of data findings (Strauss \& Corbin, 1998). A deductive method of coding was applied using a set of predefined codes within the software Atlas.ti to identify changemaker attributes and impact themes within the data. Initially, a list of changemaker attributes, identified from two sources; 'Identity, Employability and Entrepreneurship: The ChANGE Framework of Graduate Attributes' (Maxwell \& Armellini, 2019) and 'More than Simply "Doing Good:" Defining Change-maker' (Rahman, Herbst, \& Mobley, 2016), were used. A total of thirtyseven key words, both positive and negative, were identified from these papers and assigned to the data.

Initial coding indicated that pupils demonstrated an understanding of other cultures and how they tackled problems and there was evidence of the impact of growing intercultural awareness on how pupils tackled some of the tasks set during the collaboration days. It was also clear that other changemaker attributes demonstrated by pupils similarly influenced how they viewed the challenge of using technology to address the issue of physical inactivity. These observations were used to inform a second stage of axial coding that identified relationships between the codes and grouped emerging subsets of categories and overarching concepts. Figure 2 exemplifies how the transcribed quotes are linked to codes and how these are grouped within the category 'collaborative'. Each category thus relates to a changemaker attribute that groups together a set of original codes. For example, the category of being 'empathetic' includes emotional intelligence, open-mindedness and social intelligence. In total there were fifteen categories that included between two and seven characteristics identified from the data. We then identified how these categories fitted into one of two overarching concepts related to the research questions: changemaker attributes, as illustrated in Figure 3, and changemaker impact. Whilst intercultural awareness emerged as a key theme, it was decided that this was an integral changemaker attribute, rather than a separate aspect. 


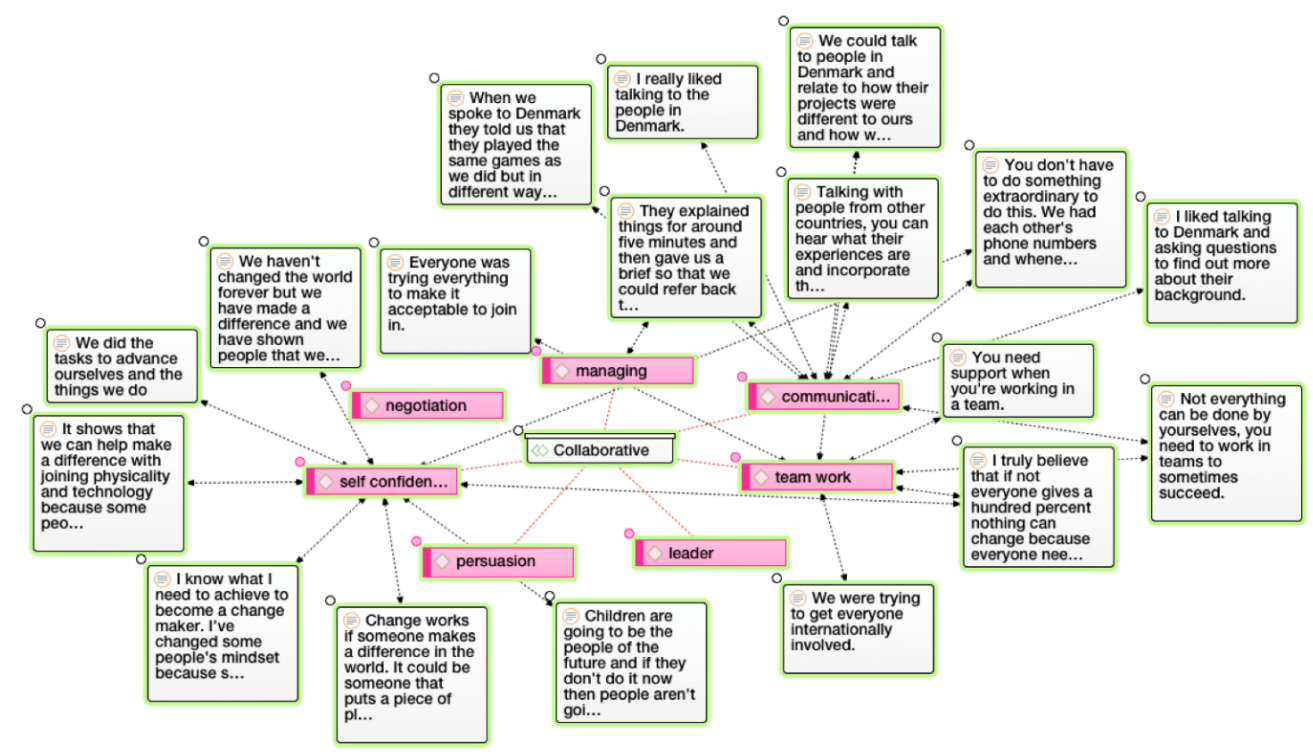

Figure 2. A thematic map of one changemaker category and codes with example quotes

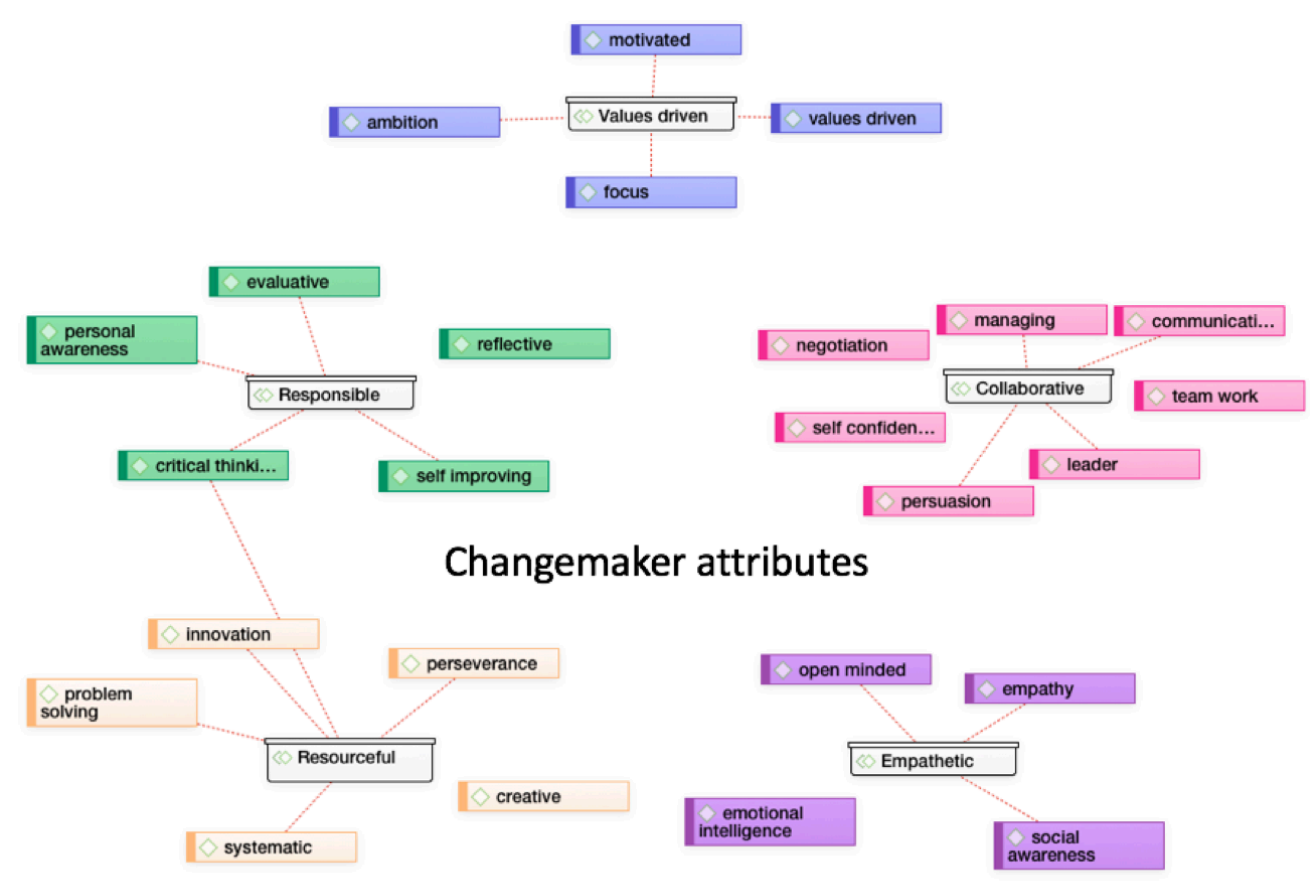

Figure 3. A thematic map showing categories and codes linked to the concept of changemaker attributes 
Table 1. A summary of the categories and concepts

\begin{tabular}{|c|c|c|c|}
\hline Concept & Categories & Frequency & Quotes \\
\hline $\begin{array}{l}\text { Changemaker } \\
\text { attributes }\end{array}$ & $\begin{array}{l}\text { Responsible, } \\
\text { collaborative, resourceful, } \\
\text { empathic, values driven, } \\
\text { sensitivity, transfer of } \\
\text { skills, social conscience, } \\
\text { globally aware, curious }\end{array}$ & $\begin{array}{l}\text { Total } 605 \text { Positive } 570 \\
\text { Negative } 35\end{array}$ & $\begin{array}{l}\text { 'Talking to other countries was } \\
\text { a good idea. Seeing how they } \\
\text { are doing their tasks will help } \\
\text { us to understand how we can } \\
\text { do ours better.' 'Not } \\
\text { everything can be done by } \\
\text { yourselves, you need to work in } \\
\text { teams to sometimes succeed.' }\end{array}$ \\
\hline $\begin{array}{l}\text { Changemaker } \\
\text { impact }\end{array}$ & $\begin{array}{l}\text { Habits, physical activity, } \\
\text { sharing experiences, } \\
\text { technology use, raising } \\
\text { awareness }\end{array}$ & $\begin{array}{l}\text { Total } 212 \text { Positive } 194 \\
\text { Negative } 128\end{array}$ & $\begin{array}{l}\text { 'We haven't changed the world } \\
\text { forever, but we have made a } \\
\text { difference and we have shown } \\
\text { people that we can help with } \\
\text { the future.' 'Things you use in } \\
\text { regular days with technology } \\
\text { can be used in different ways } \\
\text { to help enhance your life } \\
\text { physically.' }\end{array}$ \\
\hline
\end{tabular}

In presenting the findings we discuss the overarching concepts in Table 1.

\subsection{Changemaker attributes}

There was a majority of positive responses to discussions around changemaker attributes. By analysing their experiences from the collaboration days, pupils formed a judgement on how what they had learnt could impact themselves or others. They discussed how they were able to work with their international peers using digital communication and how this enhanced their technological abilities. Pupils shared ideas and felt confident in arguing possible solutions to the exergame challenge. They understood that problems can be solved through teamwork, and listening and negotiating solutions. Empathy between pupils was evident as they showed an understanding that experiences differ, and they included discussions around the type and accessibility of the technologies for their designs. Resourcefulness was shown using video communication, Twitter and by sharing AR and VR films and images of their environments to see how the Danish pupils approached the tasks. By doing this, pupils learnt new ways of approaching problems. Empathy was further demonstrated through understanding that changemaking, whilst sometimes difficult, requires togetherness and cooperation to succeed. The project influenced pupils' intercultural awareness and the English pupils were keen to work with the Danes. Pupils exhibited an awareness of some of the issues the world currently faces and a responsibility towards making change happen. Although their challenge focused on using technology to improve physical activity, they were able to apply this thinking to other issues, such as the environment.

You've got to think about things before you do it, understand it before you do it.

Using technology and physical education...you can do both at once you can do exercise whilst playing video games in your house.

We had to hold hands and interact with each other and you had to speak quite a bit because one person would have one idea and another person another, you'd have to agree on the idea. It really helped us to work together and to work as a team.

Using simple things like your phone or VR headset allows you to experience things in the world and understand more of the world and 
see how places you might have never been to and how people live their lives and how enriched they are in those places.

\subsection{Changemaker impact}

Pupils' views of their changemaker impact was that it was an ambition rather than something they could clearly see had happened. Whilst there was a majority of positive responses, the high number of negative responses suggests pupils see changemaker impact as being particularly challenging. They demonstrated an understanding that change must happen for a reason and a willingness to take responsibility in tackling the issue of motivating others to be active using technology. Pupils aspired to personal development and noted that this was an ongoing process which could occur at any point in life. The collaborative days encouraged the pupils to think about how their actions could make a difference in the future. They were able to listen and respond sensitively to pupils from other countries, and demonstrated an interest in exploring similarities and differences between the cultures and the varying approaches to tackling problems. Their curiosity to see how the pupils in Denmark approached the tasks illustrated an openness to different viewpoints. They collaborated to make decisions and communicate their ideas, taking time to reflect on each other's inputs before making a final decision as a group. Being sensitive and socially conscious was also exemplified in practice by their consideration of the other pupils' written and spoken English as they thought carefully about how they presented their instructions for non-native speakers. Additionally, they recognised that digital technology is an everyday part of their lives and understood that it can be used to improve their level of physical activity at school and at home. Pupils began to look at everyday technologies in a different light, using them to overcome language barriers by combining text, images and speech in their video calls. Pupils noticed that changing the use of technology from entertainment to exercise could impact not only their own lives but everyone else's too, and they described how they applied their skills to implement change outside school with friends, the school community and family. Altruism was also apparent in their reflections, as they appreciated that they could improve the lives of others without the need for personal recognition.

Breaking environmental boundaries would take a lot of effort but if we incorporate that in our daily lives we know we can make a change.

I know what I need to achieve to become a changemaker. I've changed some people's mindset because sometimes we're not entirely capable of doing things but that doesn't affect who we are as people and what we can do.

Anyone can change the world with a small app. One of the important things to teenagers today and to your life is being able to use technology in a way that is both fun and that helps you to improve the way you live. While being entertained you can still be active using one of the new apps.

It shows that we can help make a difference with joining physicality and technology because some people think just adults can do this but we're showing that children can do as well.

We've got to think about things to make them work and not just do it and put some effort into understanding why we're doing what we're doing. 


\section{DISCUSSION}

This study explored a model of technology-supported changemaking, with a focus on immersive technologies. Key concepts to emerge from the findings are related to:

1. Using digital technologies, such as VR and AR, to help school pupils develop changemaker attributes;

2. Using digital technologies, such as VR and AR, to help school pupils develop changemaker impact.

\subsection{Technologies developing changemaker attributes and impact}

Pupils encountered technology tools that were new to many of them and there is evidence to show that in developing and applying their skills, they demonstrated a range of changemaker attributes such as resilience, perseverance, negotiation and collaboration (Hughes \& Maas, 2017). The immersive technologies, as part of a number of technologies used in the project, not only gave pupils a creative platform through which they could innovate and invent, but facilitated a process whereby pupils could share their work with peers from other cultures and receive feedback in real time. It was evident that participation in the collaborative days encouraged pupils to consider how they could engage in changemaking and they recognised that this could have an impact on themselves and those around them in the future. Additionally, pupils were aware that, for change to be permanent, everyone must invest in that change. This amounts to a growing understanding of some of the processes involved in being a changemaker.

The findings clearly show some development of intercultural awareness in the pupils and, in the context of the project, technology created an environment that allowed this to happen. For example, the synchronous digital communication tools such as a real-time twitter wall and video conferencing lent an immediacy and interdependency to the collaboration, which made it more genuine. As a result, during the collaboration days, pupils were active in the generation of knowledge and solving of problems (Thorogood et al., 2018). Being able to share and discuss ideas virtually enabled them to connect internationally and their mutual interest led to a developing understanding of their cultures and the differing approaches their partners took to tackling problems (Hughes \& Maas, 2017). The pupils understood some of the attitudes, environments and challenges that would face their partner schools and took them into account in their game designs and instructions (Welsh \& Dehler, 2013).

\subsection{Digital making supporting changemaking}

The DLAB project has taken an innovative approach to the use of AR and VR to empower young people to build understanding of each other's environments and culture, and to design, build and share prototype exergames. Immersive technologies are increasingly a part of young people's lives and, through their inventions, our pupils showed that such technologies can be put to positive effect. Some pupils described a change in their attitude towards technology as they moved from a more passive role as consumers to become active innovators, designers and makers, a process that required significant motivation and focus. However, there is the risk that the novelty will wear off and old habits resume or are resistant to change.

There is evidence of both critical learning theory and transformational learning theory in practice, as pupils developed attributes within themselves and within a social setting. Transformational learning experiences were evident where the pupils demonstrated critical discussion of ideas and negotiation skills as part of a team (Alden-Rivers et al., 2015; Fazio-Griffith \& Ballard, 2016; Mezirow, 1991) . Critical learning theory was evident in their ability to demonstrate empathy, civil responsibility and problem 
solving (Mclaren \& Crawford, 2010; Scorza et al., 2013; United-Nations, 2015). As pupils gained metacognition of the changemaking process they developed attributes such as self-efficacy (Scorza et al., 2013).

This study was not without its challenges, not least the communication and collaboration between the countries involved. Working as a large international team across time zones and accommodating different philosophies across the partner institutions presented an ambitious programme. We worked with pupils aged between 11 and 12 , who came from a range of international, socioeconomic and educational backgrounds. The variability in experiences means it cannot be assumed that the attributes demonstrated were developed because of this study; there will be cases where some of the attributes demonstrated were already present but were seen to be applied in this context. Overall, we are aware that this research is situational in the context of this study.

\section{CONCLUSIONS AND RECOMMENDATIONS}

This study presents a set of data which suggests that the creative application of technologies such as AR and VR can develop changemaker attributes and an understanding of the changemaker process within an international project. The designing and making of $A R$ and VR artefacts is an innovative approach to using these immersive technologies as it advances users beyond a relatively passive experience to being inventors and innovators. The exchange of digital artefacts between the partner countries propelled the process of collaborative problem-solving and prompted the development of intercultural awareness. It is likely that the immersive nature of the VR and AR exchanges firstly gave the partners a more immediate impression of each other's environments as they exchanged $360^{\circ}$ images and videos, and secondly deepened their engagement with their invented exergames. AR enabled the sharing of digital artefacts that were 'almost physical' in that they are situated in real places, whereas the telepresence feature of VR instantly enabled the sensation of being transported to another place.

When technologies were applied within the context of exergaming, our pupils demonstrated a range of skills associated with changemaking and were articulate in discussing their various benefits and challenges. Evidence of changemaker impact was demonstrated through their willingness to trial solutions, share their findings more widely and commit to ongoing changes in their own activity patterns. This illustrates the enabling power of the technologies in acting as a catalyst for transformative learning.

This study also demonstrates the process of co-creating knowledge through a participatory teaching and research design in which the lecturers, teachers, pupils and student teachers were viewed as equal peers in developing and documenting the changemaking endeavour. This reshaping of the traditional research and teaching relationship proved conducive to changemaking and helped pupils to view themselves as positive agents of change (Thorogood et al., 2018).

In conclusion, we suggest that this study is pioneering in demonstrating that the creative use of immersive technologies, supported by a mix of other technologies, has the potential to create conditions for social innovation education. The use of immersive technology within this study provided an environment for pupils to demonstrate changemaker attributes such as empathy, tolerance and respect for other cultures. Through the creation of their exergames, they showed that they were aware and concerned about the issue of technology's contribution to sedentary behaviour and had the self-efficacy to be proactive in designing engaging technology-based solutions.

This study provides compelling evidence that there is potential for technologyenabled changemaking in an educational setting. Equipping pupils with the skills 
to instigate change by inventing technology-based solutions was a powerful theme. There is much to be learnt as to how this can be more widely employed across a range of educational settings and demographics of young people. Furthermore, it is evident that technology remains an intrinsic part of young people's worlds and is a highly motivating learning tool. Whilst immersive technology use in schools is in its infancy, this study indicates there is a willingness and excitement to develop it as a learning environment and pedagogical approach. We also identify the potential to develop exergaming in relation to health, physical activity, sport and physical education on a wider scale.

This study highlights an opportunity to explore other social and environmental issues using AR and VR as part of the ongoing DLAB project. The broader project offers a chance to explore the changemaking impact that working in an international study has over time. The DLAB project now moves into its second year and will be exploring how technologies might be used to address personal challenges that our participants face, a theme that is particularly relevant in the light of the recent adoption of increased remote studying and working.

\section{REFERENCES}

Alden-Rivers, B., Armellini, A., Maxwell, R., Allen, S., \& Durkin, C. (2015). Social innovation education: towards a framework for learning design. Higher Education, Skills and Work - Based Learning, 5(4), 383-400. https://doi.org/10.1108/HESWBL-04-2015-0026

Azuma, R. (1997). A survey of augmented reality. Presence: Teleoperators \& Virtual Environments, 6(4), 355-385. Retrieved from https://www.cs.unc.edu/ azuma/ ARpresence.pdf

BMJ. (2008). Qualitative research methodologies: ethnography. The British Medical fournal, 337, 512-514. https://doi.org/10.1136/bmj.a1020

British-Educational-Research-Association. (2018). Ethical Guidelines for Educational Research..

Carmigniani, J., Furht, B., Anisetti, M., Ceravolo, P., Damiani, E., \& Ivkovic, M. (2011). Augmented reality technologies, systems and applications. Multimedia Tools and Applications, 51(1), 341-377. https://doi.org/10.1007/s11042-010-0660-6

Cohen, L., Manion, L., \& Morrison, K. (2018). Research Methods in Education. London, England: Routledge.

Dziedziewicz, D., Gajda, A., \& Karwowski, M. (2014). Developing children's intercultural competence and creativity. Thinking Skills and Creativity, 13, 32-42. https://doi.org/ 10.1016/j.tsc.2014.02.006

Faric, N., Yorke, E., Varnes, L., Newby, K., Potts, H. W., Smith, L., ... Fisher, A. (2019). Younger Adolescents' Perceptions of Physical Activity, Exergaming, and Virtual Reality: Qualitative Intervention Development Study. FMIR Serious Games, 7(2), 126-134. https://doi.org/10.2196/11960

Fazio-Griffith, L., \& Ballard, M. B. (2016). Transformational Learning Theory and Transformative Teaching: A Creative Strategy for Understanding the Helping Relationship. Journal of Creativity in Mental Health, 11(2), 225-234. https://doi.org/ 10.1080/15401383.2016.1164643

Hughes, J., \& Maas, M. (2017). Developing 21st Century Competencies of Marginalized Students Through the Use of Augmented Reality (AR). LEARNing Landscapes, 11(1), 153-169. Retrieved from https://files.eric.ed.gov/fulltext/EJ1253490.pdf

Kara, H. (2015). Creative research methods in the social sciences: A practical guide. Bristol, England: Policy Press.

Lin, C. Y., \& Chang, Y. M. (2015). Interactive augmented reality using Scratch 2.0 to improve physical activities for children with developmental disabilities. Research in Developmental Disabilities, 37, 1-8. https://doi.org/10.1016/j.ridd.2014.10.016 
Maxwell, R., \& Armellini, A. (2019). Identity, employability and entrepreneurship: the ChANGE framework of graduate attributes. Higher Education, Skills and Work-Based Learning, 9(1), 76-91.

Mclaren, P., \& Crawford, J. (2010). Critical pedagogy. In C. Kridel (Ed.), Encyclopedia of curriculum studies (pp. 148-149). California: SAGE.

Mezirow, J. (1991). Transformative Dimensions of Adult Learning. San Francisco, CA: JosseyBass.

Mochizuki, Y. (2019). Rethinking Schooling for the 21st Century: UNESCO-MGIEP's Contribution to SDG 4. The fournal of Record, 12(2), 88-92. https://doi.org/10.1089/ sus.2019.29160

Pink, S. (2013). Doing visual ethnography. London, England: SAGE.

Rahman, R., Herbst, K., \& Mobley, P. (2016). More than simply "doing good:" A definition of Changemaker: what children, truckers, and superheroes all have in common. Retrieved from https://www.evansville.edu/changemaker/downloads/more-than-simply-doing -good-defining-changemaker.pdf

Schon, D. A. (1984). The reflective practitioner: How professionals think in action. New York, NY: Basic books.

Scorza, D., Mirra, N., \& Morrell, E. (2013). It should just be education: critical pedagogy normalized as academic excellence. International fournal of Critical Pedagogy, 4(2), 15-34. Retrieved from http://libjournal.uncg.edu/ijcp/article/view/337/365

Strauss, A., \& Corbin, J. (1998). Basics of qualitative research techniques. Thousand Oaks, CA: Sage publications.

Thornton, T., Ernst, J. V., \& Clark, A. C. (2012). Augmented reality as a visual and spatial learning tool in technology education: Potential exists for AR to be incorporated in not only STEMeducation, but across all disciplines. Technology and Engineering Teacher, 71(8), 18-21.

Thorogood, J., Azuma, F., Collins, C., Plyushteva, A., \& Marie, J. (2018). Changemakers and change agents: encouraging students as researchers through Changemaker's programmes. Journal of Geography in Higher Education, 42(4), 540-556. https://doi.org/ 10.1080/03098265.2018.1460804

United-Nations. (1989). Convention on the Rights of the Child.

United-Nations. (2015). Transforming our world: The 2030 Agenda for Sustainable Development. New York: UN.

Welsh, M. A., \& Dehler, G. E. (2013). Combining Critical Reflection and Design Thinking to Develop Integrative Learners. Fournal of Management Education, 37(6), 771-802. https://doi.org/10.1177/1052562912470107

Wu, H. K., Lee, S. W., Chang, H. T., \& Liang, J. C. (2013). Current status, opportunities and challenges of augmented reality in education. Computers \& Education, 62, 41-49. https://doi.org/10.1016/j.compedu.2012.10.024 